\section{Engineering Research Journal \\ Faculty of Engineering \\ Menoufia University}

\title{
An Investigation of Using Microchannel Condenser to Improve the Performance of Air Conditioning Unit
}

\author{
Mostafa A. Abdel-Baky ${ }^{1}$, Mousa M. Mousa' ${ }^{1}$ and Abdel-Fattah A. Koraim ${ }^{2}$ \\ 1 Mech. Powe Engg. Dept, Faculty of Engg., Menoufia Univ., Shebin El-Kom, Egypt. \\ 2 An Engineer, Toshiba El-Arapy Company, Quisna, Menoufia, Egypt
}

\begin{abstract}
In the recent years, many researches have been focused towards the new technology in heat exchangers. Besides, the economy of manufacturing takes up a great attention of scientific works. Through this work the use of microchannel condenser achieves increase in energy. The study was conducted on two air conditioning units utilize R-22 as a refrigerant and having different cooling capacities $3516 \mathrm{~W}$ and $5274 \mathrm{~W}$. The results showed that the use of microchannel condenser achieves increase in Energy Efficiency Ratio (EER) which reflected on the total efficiency of the device and reduce energy cost. The obtained results indicated that, the use of microchannel condenser led to increase in EER by (4.3:11.3\%) for the first unit and and $(9.5: 29 \%)$ for the second one compared with that unit use FTC. Also, the use of MChC led to decrease the pressure drop by (20\%:30\%) while the convective heat transfer coefficient is improved by (61.6:84.1\%).
\end{abstract}

Keywords: Microchannel condenser; Microchannel heat exchanger; Window air conditioner; Refrigeration; Energy efficiency ratio.

\section{1- Introduction}

Todays with the increase of industries which results in increasing energy consumption, many researches have been conducted to develop the refrigeration system in order to reduce and save energy. One of these developments is focused on replacing the finned tube condenser with micro-channel one in air conditioning units. Besides, the heat transfer through microchannel has very potential of wide applications in cooling such as high-power density microchips in the computer processing unit (CPU). The micro power systems and even many other large scales thermal systems require effective cooling capacity. This is a result of the micro size of the cooling system which not only significantly reduces the weight load, but also enhances the capability of removing much greater amount of heat than any of large scales cooling systems.

Many efforts have been conducted in using microchannel condensers instead of finned tube one. The performance of refrigeration system using microchannel condenser, with R-134a, was analyzed experimentally and numerically by Patil et al. [1]. The results obtained were compared with round condenser having the same size. The tests were taken according to Air conditioning and Refrigeration Institute (ARI) condition. It was indicated that the microchannel condenser was more effective at various loads, operating conditions and refrigerants. The COP of microchannel condenser was around 7:8 \% higher than the round tube one. The condensing temperature was decreased $2.5^{\circ} \mathrm{C}$ when a microchannel condenser was used instead of classic condenser and the refrigerant pressure drop was also decreased from $166 \mathrm{kPa}$ in the round-tube condenser to $57 \mathrm{kPa}$ in the microchannel condenser. The seasonal energy efficiency ratio (SEER) of a residential air conditioning system having either a finned tube condenser or a microchannel condenser was experimentally investigated by Yun et al [2]. For that investigation, a commercially available $7 \mathrm{~kW}$ capacity residential air conditioning system having a finned tube condenser served as the base system. It was found that microchannel condensers offer a higher volumetric heat exchange. The test results showed that the system with a microchannel condenser has the coefficient of performance increased by $6: 10 \%$ and the SEER increased by $7 \%$ as compared with those of the base system. Moreover, the condensing pressure of the system is decreased by $100 \mathrm{kPa}$ and the pressure drop across the condenser is decreased by $84 \%$. The microchannel condenser enhances the SEER of the residential air conditioning system by providing better heat transfer at reduced pressure drop.

The heat transfer coefficient for mini-channel aluminum tube condenser was studied by Fernando et al. [3]. It was reported that the overall heat transfer coefficient of the micro-channel condenser was $62 \%$ higher than that of a plate-type one. Chen et al. [4] 


\section{Mostafa A. Abdel-Baky, Mousa M. Mousa, Abdel-Fattah A. Koraim, "An Investigation of Using Microchannel Condenser to Improve the Performance of Air Conditioning Unit"}

studied the performance of the liquid-vapor separation condenser (LSC) and compared it with that of the system having a baseline fin-and-tube one at various ambient temperatures from 29 to $43{ }^{\circ} \mathrm{C}$. The results obtained, for R-22 as refrigerant, showed that both of the cooling capacity and energy efficiency ratio (EER) of the two systems were almost the same. The LSC is having just $67 \%$ of the heat transfer area of the baseline condenser.

Park and Hrnjak [5] studied the performance of different types condensers for the residential air conditioning systems charged with R-410A. Two airconditioning systems, one with a microchannel condenser and the other with a round-tube condenser, were experimentally examined, while the other components of the two systems were identical except the condensers. The COP of the system with the microchannel condenser was $13.1 \%$ higher than that with the round tube condenser.

Roth et al. [6] indicated in their study that, the use of $\mathrm{MChC}$ instead of round tube one, with $\mathrm{R}-22$ as a refrigerant, improves the EER from 11 to $12.2 \%$. Hu and Chao [7] found that microchannel condensers exhibit higher heat transfer coefficients with the same Reynolds number. The condensation heat transfer coefficient was higher than that in the tubes with the diameter of centimeter. Pressure drops in the microcondensers with smaller channels were higher due to the increased transition loss.

Bhatkar, et al [8] investigated experimentally the performance of compression refrigeration system using microchannel condenser with R134a and drop in substitute R152a with aluminum microchannel condenser at condensation temperature of $48{ }^{\circ} \mathrm{C}$ and evaporation temperature varied from -10 to $15{ }^{\circ} \mathrm{C}$. It was found that, the product of overall heat transfer coefficient and surface area of the condenser (UA) were more for microchannel condenser than conventional condenser. The pressure drop was less in microchannel condenser than conventional condenser by around 0.1 to 0.5 bar. Also, the increasing of saturation temperature showed a significant effect on decreasing the pressure drop. Kandlikar [9] conducted a review for history, advances, and challenges in liquid flow and flow boiling heat transfer in microchannels. It was found that, the use of micro-scale passages improved heat transfer. It was recorded that, microchannels are gateway to flow modification through such Nano-scale surface enhancement configurations.

Jhariya, et al [10] studied two condensers in the same air-conditioning system. One with round tubes and the second one with flat microchannel tubes. The window air conditioning systems was designed for R-22 and its alternative R-410A. The experiments were conducted at atmospheric temperatures ranged $35{ }^{\circ} \mathrm{C}$ to $41{ }^{\circ} \mathrm{C}$. The performance of the air conditioner with R-410A was compared with the baseline performance with R22. For R-22, the heat transfer in the round tube condenser was $0.75 \%$ of that of microchannel condenser; while for R-410A it was $2.39 \%$ higher than the microchannel condenser (The EERs of the system with microchannel condenser is higher than the system with the round tube condenser). The mass flow rate, heat rejected in the condenser and the compressor power of the system with microchannel condenser is lower than the system with the round tube condenser. The previous review indicates little attention of studying the performance of the Air Conditioning unit with microchannel condenser at various operating conditions.

\section{Aim and Research Significance}

The main objective of this study is to experimentally investigate the performance of microchannel condenser $(\mathrm{MChC})$ in comparison with traditional round finned tube condenser (FTC) at different outdoor temperature and different capacities size of air conditioning unit, at steady state condition. Also, comparing the convective heat transfer coefficient for traditional finned tubes and the new microchannel condenser is performed.

\section{Experimental Program}

The experimental program was conducted on the system that shown schematically in Fig. 1. The system consists of split air conditioning units, two test rooms and experimental instrumentations. The air conditioning systems were charged with Freon R-22. Four split air conditioning units were taken into consideration in order to be experimentally tested. Two units of them were having $3516 \mathrm{~W}$ cooling capacity for each one while the other two units were $5274 \mathrm{~W}$ capacity for each one. The two indoor units for each cooling capacity are identical. They were finned tubes coils. For each two, the condenser was chosen of two types for the purpose of study. First type was finned tubes condenser while the other one was microchannel condenser as indicated in Table (1). The indoor and outdoor units are installed in air conditioned two rooms in order to carry out the experiments at variable conditions. 


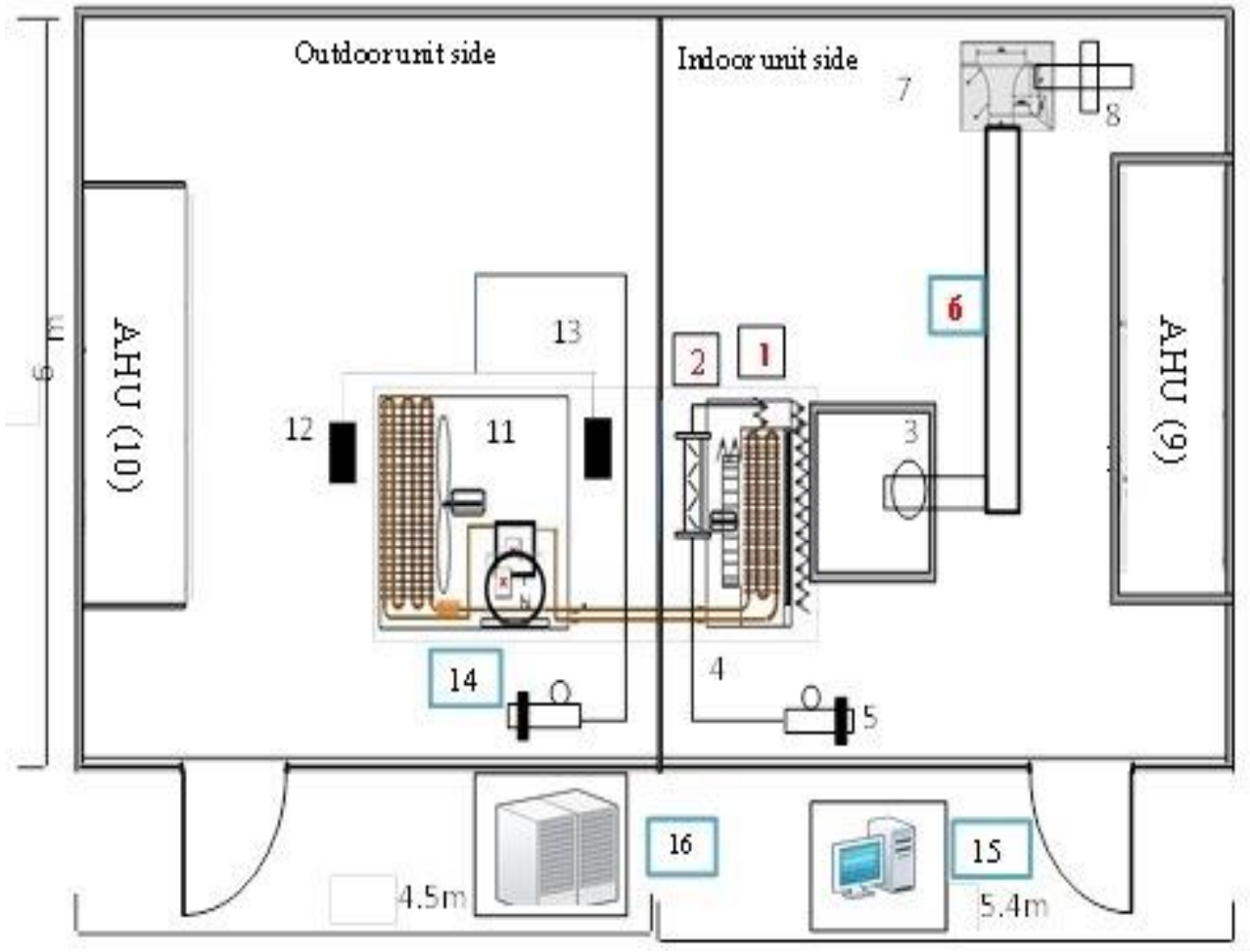

1- Indoor unit.

2- Air inlet samples hub for indoor unit.

3- Receiving chamber.

4- Air sample hose for indoor unit.

5- Psychometric box indoor unit.

6- Air outlet hose.

7- Air flow measurement tunnel.

8- Variable speed blower.
9- AHU air handling unit for indoor side.

10- AHU air handling unit for outdoor side.

11- Outdoor unit.

12 -Air sampling unit at air inlet to outdoor unit.

13- Air sampling unit at air outlet of outdoor.

14- Psychometric box outdoor unit.

15- Measuring instruments panel.

16- Data output unit.

Fig. 1 Schematic layout of the experimental system

Table 1 Tested and Geometric characteristics for the two condensers.

\begin{tabular}{|l|c|c|c|c|}
\hline \multirow{2}{*}{} & \multicolumn{4}{|c|}{ Unit cooling capacity } \\
\cline { 2 - 5 } & \multicolumn{2}{|c|}{$3516[\mathrm{~W}]$} & \multicolumn{2}{c|}{5217 [W] } \\
\cline { 2 - 5 } & FTC & MChC & FTC & MChC \\
\hline Rated cooling capacity & 3156 & 3156 & 5274 & 5274 \\
\hline Refrigerant & R-22 & R-22 & R-22 & R-22 \\
\hline Face length & $77 \mathrm{~cm}$ & $74.5 \mathrm{~cm}$ & $78 \mathrm{~cm}$ & $76 \mathrm{~cm}$ \\
\hline materials & Copper & Aluminum & Copper & Aluminum \\
\hline Inside dimensions [mm] & $\mathrm{d}=4.8$ & $1.3 * 1.3$ & $\mathrm{~d}=7$ & $1.3 * 1.3$ \\
\hline tube & 4 & 30 & 4 & 30 \\
\hline Indoor temperature & \multicolumn{4}{|c|}{27 dry-bulb \& 19 wet-bulb } \\
\hline Compressor & \multicolumn{4}{|c|}{ Straight capillary tube } \\
\hline Capillary tube & \multicolumn{5}{|c|}{} \\
\hline
\end{tabular}




\section{Mostafa A. Abdel-Baky, Mousa M. Mousa, Abdel-Fattah A. Koraim, "An Investigation of Using Microchannel Condenser to Improve the Performance of Air Conditioning Unit"}

The indoor unit is installed on a stand frame as shown in Fig. 2 and the all are attached to an air receiving chamber. The received chamber is equipped with sensors for measuring the temperature and pressure. Air sampling hub is installed at air inlet to the indoor unit. Samples of air that enters to the indoor unit were taken through 80 holes distributed on a hub, as shown in Fig. 3, in order to obtain the mean value of the measured parameter. The collected air samples were taken through an insulated hose to a measuring psychometric box in order to measure the dry and wet bulb temperatures of air. The inside condition of the indoor unit test room was changed and adjusted by a central air handling unit in order to maintain the inside condition according to British standard (BS ISO 5151:2010).

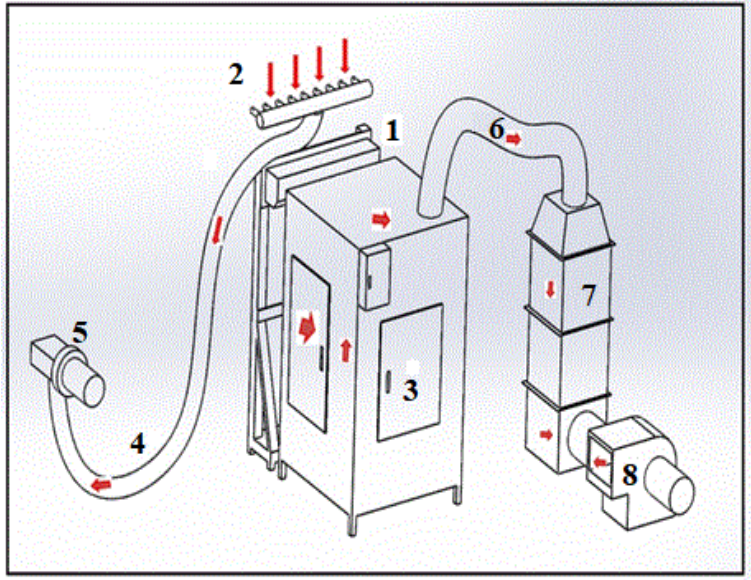

1-Indoor unit

2- Air inlet samples

3- Air chamber 4-Air sample hose,

5- Dry and wet bulb measuring,

6- Air outlet hose,

7- Air flow measurement tunnel,

8- Air outlet blower.

Fig. 2 Indoor unit test room

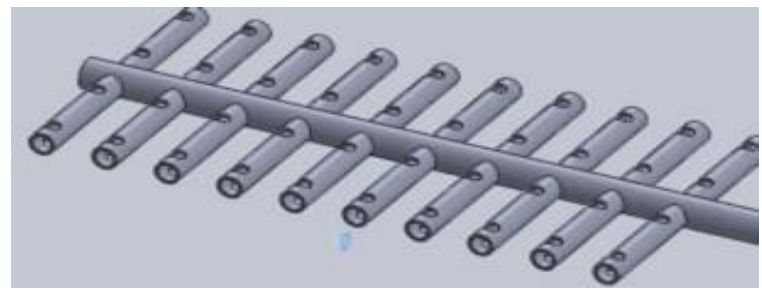

Fig. 3 Air sampling hub

The air which be cooled through the indoor unit was collected inside the receiving chamber in order to measure its pressure as well as its dry and wet bulb temperatures. The chamber was $0.4 \times 0.4 \times 0.7 \mathrm{~m}$. It was covered with air tight lid and insulated with $50 \mathrm{~mm}$ thickness expanded polyurethane foam with covered steel faces. The pressure inside the chamber was measured by the aid of a barometer. The dry and wet bulb temperature of the air was measured at chamber inlet and outlet. In order to measure the wet bulb temperature of the air, an automatic water recharge device and a water supply vessel was equipped, as shown in Fig. 4.

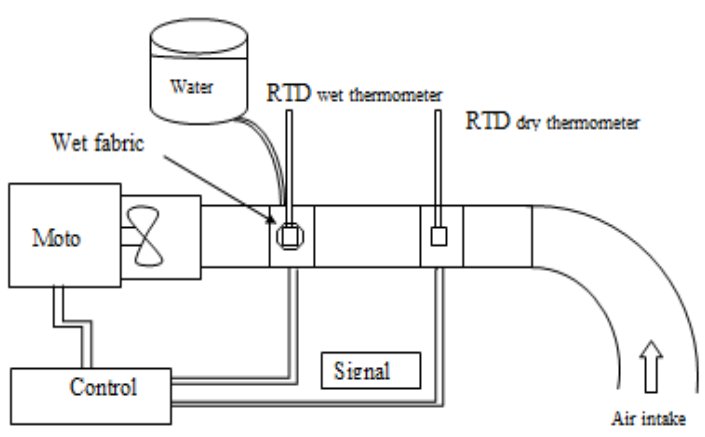

Fig. 4 Psychometric box

The cooled air carried out in air outlet hose enters the nozzles tunnel, Fig. (5). The tunnel was made of 2.3 $\mathrm{mm}$ thickness with inside cross section area of $450 \times 500 \mathrm{~mm}$ and length $(980 \mathrm{~mm})$. Three nozzles were installed inside a steel tunnel as shown in the figure. They were compliant with JIS $\Phi 50, \Phi 70, \Phi 100$ $\mathrm{mm}$. Each nozzle is electronically opened according to the rated cooling capacity.

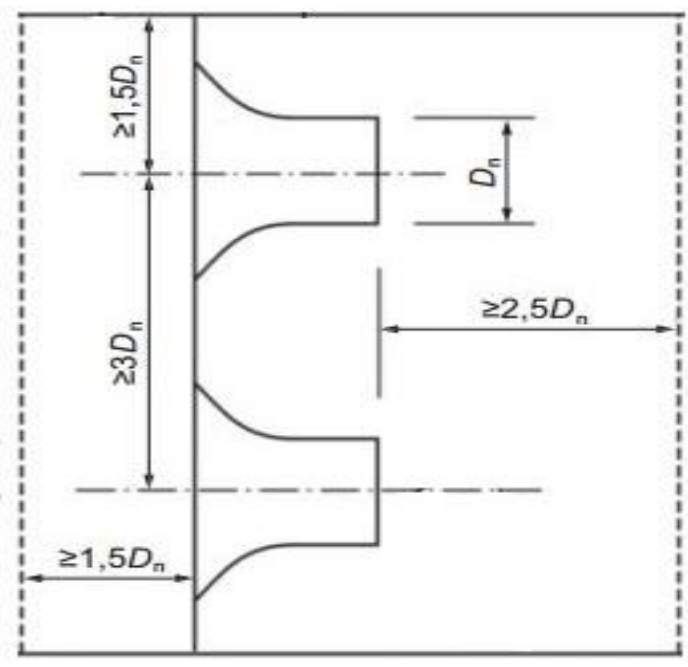

$\mathrm{D}_{\mathrm{n}}=\mathrm{JIS} \Phi 50, \Phi 70$

Fig. 5 Air flow nozzle

The outdoor unit was also installed on a stand frame. The unit was installed in an insulated room. The room was supplied by air handling unit in order to maintain its inlet temperature and relative humidity at the required test conditions. Two sampling hubs were attached to the unit at air inlet and outlet for the purpose of measuring the dry and wet bulb 


\section{Mostafa A. Abdel-Baky, Mousa M. Mousa, Abdel-Fattah A. Koraim, " An Investigation of Using Microchannel Condenser to Improve the Performance of Air Conditioning Unit"}

temperature. The power consumed by the compressor, as well as the electric current were measured by a wattmeter and an ammeter. The inlet volt was fixed at $220 \mathrm{~V}$ by the aid of stabilizer. Samples of air enters and leaves to the outdoor unit were taken to temperature measuring purposes as the same I indoor unit. The inside condition of the outdoor unit test room was changed and adjusted by a central air handling unit in order to be simulated to the change of ambient condition.

Platinum RTDs (Resistance Temperature Detectors) thermometers were used for measuring the temperature of the samples of air. These sensing elements were made of pure platinum wire coil (wire wound) encapsulated in ceramic or glass, or a thin film platinum deposited on a ceramic substrate. Platinum RTDs have a positive temperature coefficient. Their electrical resistance increases as temperature rises in a known and repeatable manner. Their linearity and unmatched long term stability firmly establish platinum RTD elements as an ideal sensor for most industrial applications. Thin film elements offer performance equal to standard wire wounds, but with improved cost, size and convenience. The thermometers measuring range was $\left(-200\right.$ to $\left.200{ }^{\circ} \mathrm{C}\right)$, Accuracy: $\pm\left(0.1 \%\right.$ of reading $\left.+0.2^{\circ} \mathrm{C}\right)$.

A control and measuring panel was located in the monitoring room for installing of meters and reading sensors and a computer interface, Fig. 6. The outputs of control or monitoring instruments were displayed. Those instruments involve part of a system that users could access, to see all of the indicators and parameters of the air conditioning unit such as (dbt, wbt, volt, ampere......etc.) on the screen. The measured data were transferred to a computer to be recorded. The control panels are often equipped with push buttons and analog instruments, digital devices in many cases touchscreens are used for monitoring and control purposes.

Digital power monitoring systems support simple monitoring tasks as well as more complex tasks, such as power trending, controlling and identification of sources of energy consumption and load profiles of power supply segments. The digital power meters were used to indicate the voltage difference and the current intensity, as well as the power of the air conditioning device, for calculating the air conditioning unit performance. The max input to digital power monitoring was: voltage: $1000 \mathrm{~V}$, current: $20 \mathrm{~A}$. as shown in, Fig. 7.

\begin{tabular}{|l|l|}
\hline $\begin{array}{l}\text { voltage and current } \\
\text { accuracy }\end{array}$ & $\begin{array}{l} \pm(0.1 \% \text { of reading }+0.1 \% \text { of } \\
\text { range })\end{array}$ \\
\hline
\end{tabular}

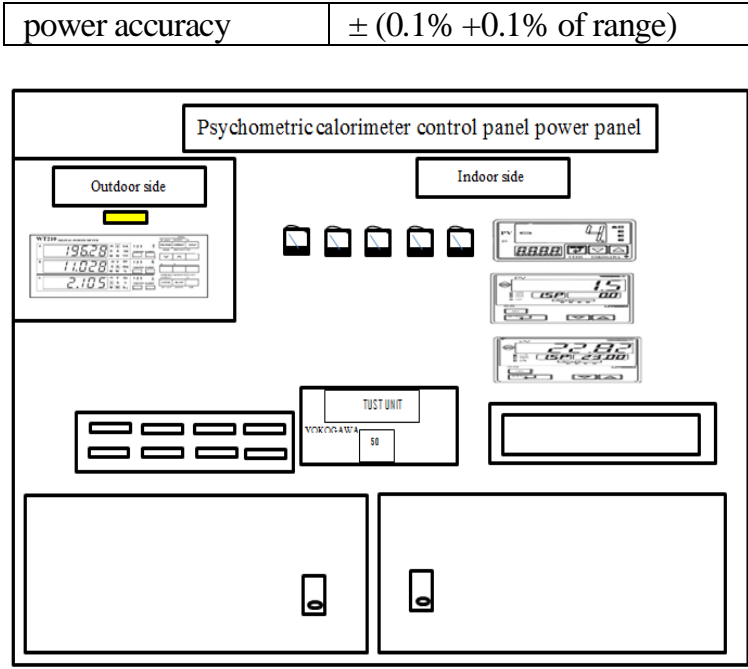

Fig. 6 control and measuring panel

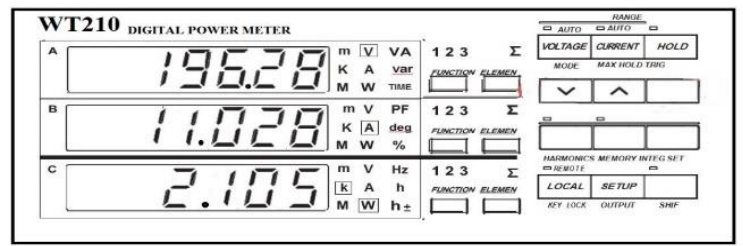

Fig. 7 Digital Power Meter

A computerized data Acquisition system was installed for collecting and recording data to test result process designed specifically for use with the test laboratory. The system was including a personal computer with necessary I/O hardware, printer, software and analog data acquisition instrument.

\section{3- Results and Discussion}

The obtained experimental data explain the effect of using micro-channel condenser in air conditioning unit. The HVAC systems may be affected by many parameters such as; energy efficiency ratio EER, condenser pressure drop, heat transfer coefficient calculation. So, the researches should be directed towards the improvement of environment in the various fields.

\section{1 Energy Efficiency Ratio EER}

The Energy Efficiency Ratio "EER" is the ratio of the total cooling capacity $Q$ achieved by the unit to the effective power input to the device at any given set of rating conditions. For cooling, it could be written as:

$$
E E R=\frac{\dot{Q}}{\text { Power }}=\frac{\dot{Q}}{\text { Power }_{c}+\text { Power }_{\text {fan }}}
$$




\section{Mostafa A. Abdel-Baky, Mousa M. Mousa, Abdel-Fattah A. Koraim, "An Investigation of Using Microchannel Condenser to Improve the Performance of Air Conditioning Unit"}

The EER is affected by the type of condenser as indicated in Fig. (8). It is clearly seen that the EER decreases with the increase of ambient condition. This is because the increase of ambient temperature results in an increase of the compressor work done, which in turn reflected on the power. It was observed that, for the unit has $3516 \mathrm{~W}$ rating cooling capacity, the increases in EER ranges between 0.42 and 0.6 when $\mathrm{MChC}$ was installed than the case of FTC at the testing temperature range. The percentage increase in EER. is between $4.3 \%$ to $11.3 \%$ as indicated in Fig. (9). For the unit of $5274 \mathrm{~W}$, EER increases by 0.9 to 1.55 in case of installing $\mathrm{MChC}$. The corresponding percentage increase is between $9.47 \%$ and $29 \%$. It is known that the increase in EER support and implement the requirements of the Egyptian organization for standardization and quality. Raise the classification of air-conditioning device with energy efficiency card, and consequently increasing the competitiveness of products in the market. When EER increasing given the same energy source and operating conditions, a higher EER heat pump will consume less purchased energy than one with a lower EER the overall environmental impact of a heating or air conditioning installation depends on the source of energy used as well as the EER of the equipment. The operating cost to the consumer depends on the cost of energy as well as the EER or efficiency of the unit.

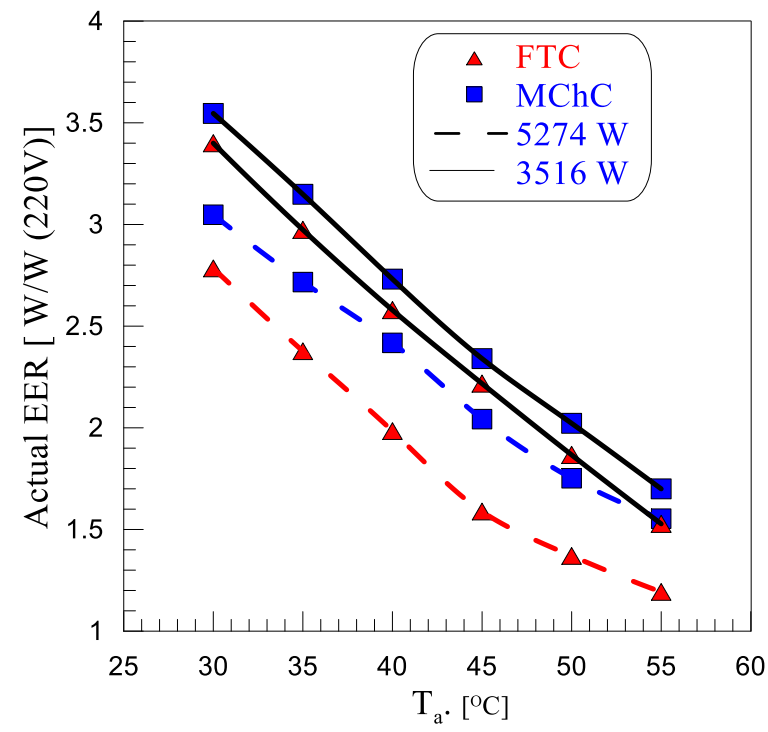

Fig. 8 Effect of ambient temperature on the EER at $220 \mathrm{~V}$

The results obtained, for percentage increase in EER, in the present work were compared with others those work at nearly the same operating conditions and illustrated in Table (2) and Fig. (9). It is noticed that, the percentage increase achieved by Jhariya et al. [10] was (6.6 and $6.8 \%)$ for the two cases at which the tests were conducted. Chaikhumrop and Trutassanawin [12] achieved percentage increase of $(1.14,2.8,3.08)$ $\%$ for the three test cases. The figure indicates that percentage increase in EER achieved by the present work is nearly close to that obtained by [10] and higher than that obtained by the other one.

Table 2: Comparison of percentage improvement in EER

\begin{tabular}{|c|c|c|c|c|}
\hline $\begin{array}{l}\text { Paper } \\
\text { No. }\end{array}$ & $\begin{array}{c}\text { Unit } \\
\text { C. C. } \\
{[\mathrm{W}]}\end{array}$ & $\mathrm{T}_{\mathrm{a}}\left[{ }^{\circ} \mathrm{C}\right]$ & Freon & EER \\
\hline 10 & 3516 & 35,41 & R22 & 6.6: $6.8 \%$ \\
\hline 12 & 5275 & $\begin{array}{c}35,38 \\
42\end{array}$ & R22 & $\begin{array}{c}1.14,2.8, \\
3.08 \%\end{array}$ \\
\hline \multirow{2}{*}{$\begin{array}{c}\text { Present } \\
\text { work }\end{array}$} & 3516 & \multirow{2}{*}{$30-55$} & \multirow{2}{*}{ R-22 } & $4.3: 11.3 \%$ \\
\hline & 5274 & & & $9.5: 29 \%$ \\
\hline
\end{tabular}

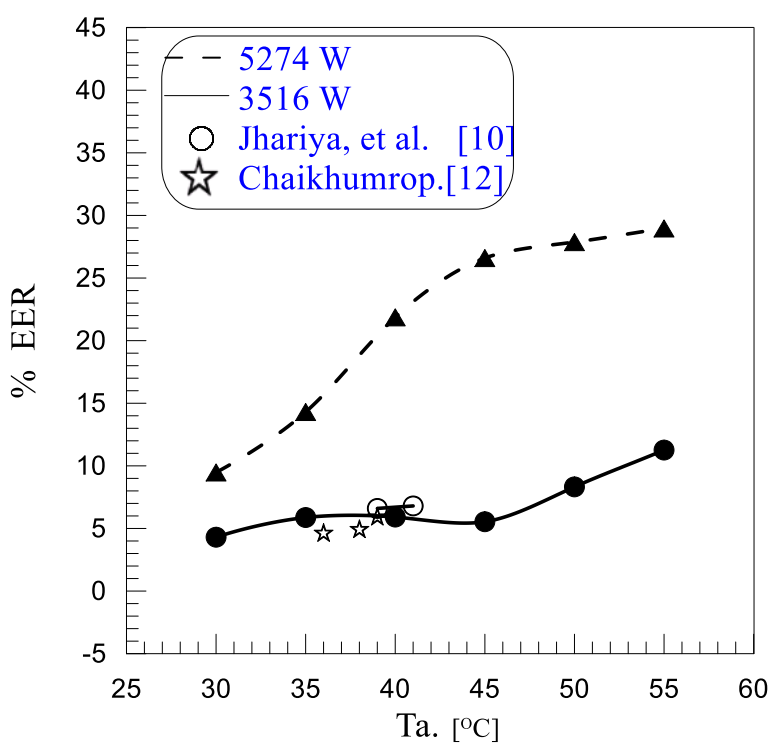

Fig. 9 Effect of ambient temperature on the percentage improvement in EER

\section{2 Condenser Pressure Drop:}

The pressure drop in condenser is due to two reasons, friction loss and local loss. Theoretically, the friction loss is given by Darcy correlation [12] as indicated in equation (2):

$\Delta p=f\left(\frac{l}{d}\right)\left(\frac{\rho u^{2}}{2}\right)$

The local loss is due to any of the following: pipe entrance or exit, sudden expansion or contraction, gradual expansion or contraction, bends, elbow, tee connection and other fittings. Equation (3) represents the local pressure drop [12]: 


\section{Mostafa A. Abdel-Baky, Mousa M. Mousa, Abdel-Fattah A. Koraim, " An Investigation of Using Microchannel Condenser to Improve the Performance of Air Conditioning Unit"}

$$
\Delta p=\frac{1}{2} K \rho u^{2}
$$

In order to indicate the effect of using micro-channel condenser on the condenser pressure drop, the condenser inlet and outlet pressure was measured by digital electronic pressure transmitter at various ambient temperatures. Fig. (10) illustrates the effect of ambient temperature on the condenser inlet and outlet pressure respectively for $5274 \mathrm{~W}$ unit. Generally, it is indicated, that the condenser inlet pressure is ranged between 13.4 bar and 24.2 bar for the unit with finned round tube condenser. A small change in inlet pressure is observed for microchannel condenser (13.2 and 24.1 bar). This small change in the recorded pressure is expected because this pressure is related to the compressor outlet pressure and has no relation to the condenser type. The figure indicates also the condenser outlet pressure for the same unit. The condenser outlet pressure for outdoor unit is ranged between 12.6 bar and 22.3 bar for the unit with finned round tube condenser while a small change 12.6 bar to 23 bar for the unit used microchannel condenser is observed.

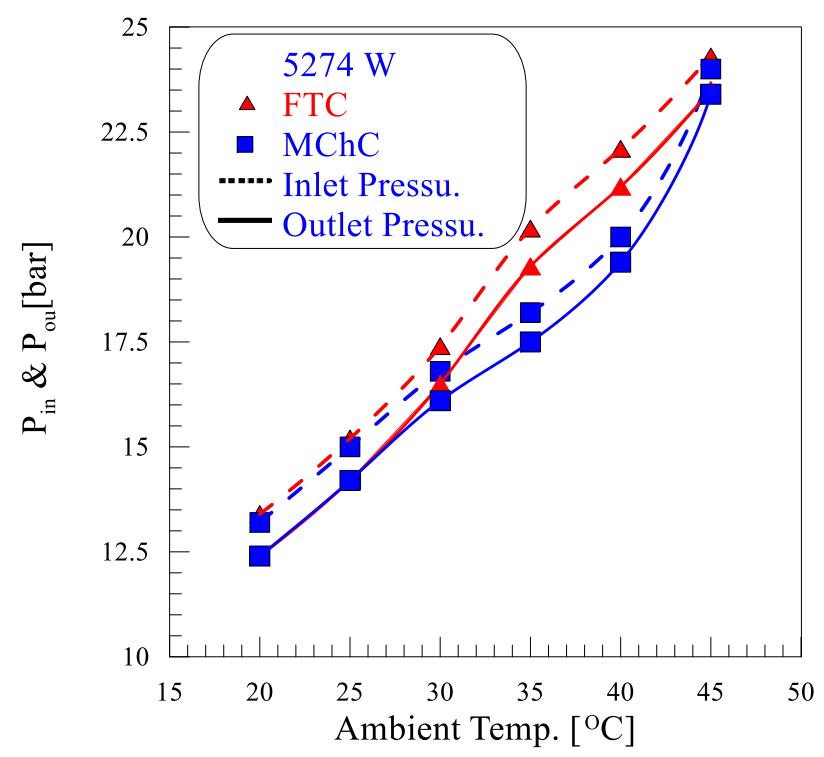

Fig. 10 Effect of ambient temperature on the actual condenser inlet $\&$ outlet pressure [bar]

Figure (11) indicates the experimental and theoretical condenser pressure drop for $5274 \mathrm{~W}$ cooling capacity unit for the two types of condenser (round tube and microchannel) at different ambient temperature. Experimentally, the condenser pressure drop is ranged between 0.8 and 1 bar for the unit with finned round tube condenser while it was change to 0.6 to 0.8 bar for the unit used microchannel condenser. For all tests, the experimental pressure drop of the microchannel condenser is lower than that of the finned tube condenser by $(20: 33.3 \%)$.

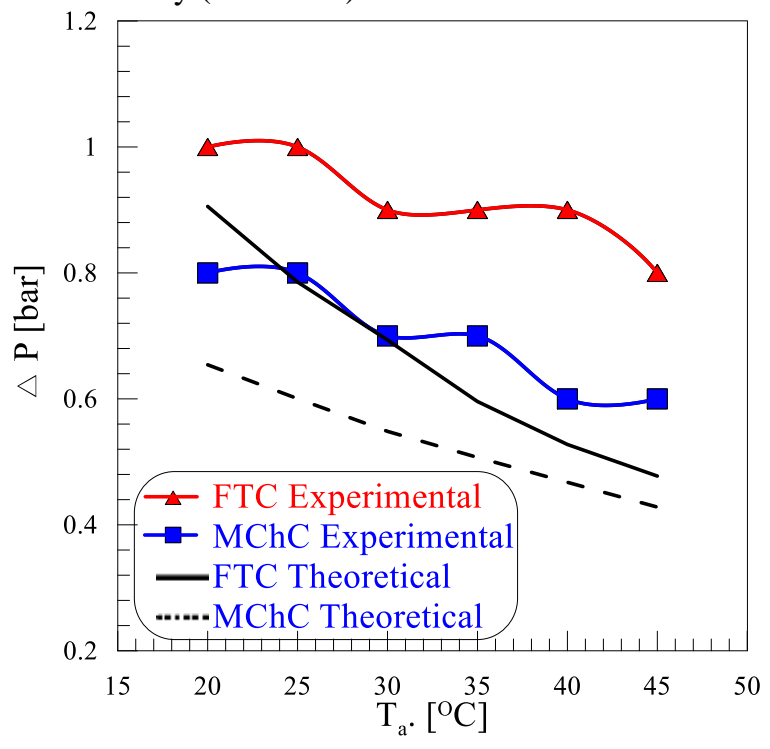

Fig. 11 Effect of ambient temperature on condenser pressure drop.

Theoretical calculation indicated that, the condenser pressure drop changes within the range from 0.48 bar to 0.91 bar for the unit with finned tube condenser while it was changed within the range from 0.43 bar to 0.65 bar for the unit used microchannel condenser. For all theoretical calculations, the pressure drop of the micro-channel condenser is lower than that of the finand-tube condenser by $(10.3: 27.8) \%$. This lower pressure drop of the microchannel condenser can be explained by two reasons. One is the increase of the refrigerant flow cross sectional area of microchannel condenser by $48 / 23$ parallel tubes than that of the finned tube condenser. The other is shorter refrigerant path of the microchannel condenser than that of the fin-and-tube condenser.

Clearly, this explains the frequently noted misconception that condensers with small diameter tubes have a higher refrigerant side pressure drop than those with larger tubes. The effect of reducing the diameter is offset by the increased number of parallel channels. Certainly, the limit in controlling the refrigerant side pressure drop in a parallel flow microchannel condenser is a single-pass arrangement.

The results obtained, for percentage decrease in pressure drop, in the present work were compared with the others those work at nearly the same operating conditions and illustrated in Table (3) and Fig. (12). It is noticed that, the percentage increase achieved by 


\section{Mostafa A. Abdel-Baky, Mousa M. Mousa, Abdel-Fattah A. Koraim, "An Investigation of Using Microchannel Condenser to Improve the Performance of Air Conditioning Unit"}

Patil et al. [1] was 65\%, Yun et al [2] achieved percentage increase of $84 \%$ while Bhatkar, et al [8] achieved $18 \%$. The figure indicates that percentage increase in pressure drop achieved by the present work is nearly close to that obtained by [8] and less than that obtained by the other two.

Table 3: Comparison of percentage improvement in condenser pressure drop.

\begin{tabular}{|c|c|c|c|c|}
\hline $\begin{array}{c}\text { Paper } \\
\text { No. }\end{array}$ & $\begin{array}{c}\text { Unit } \\
\text { C. C. } \\
{[\mathrm{W}]}\end{array}$ & $\mathrm{T}_{\mathrm{a}}\left[{ }^{\circ} \mathrm{C}\right]$ & Freon & $\Delta \mathrm{P}_{\mathrm{c}}$ \\
\hline 1 & 1172.3 & 34 & $\mathrm{R} 134 \mathrm{~A}$ & $65 \%$ \\
\hline 2 & 7000 & 35 & $\mathrm{R} 22$ & $84.0 \%$ \\
\hline 8 & 3516 & $\begin{array}{c}\mathrm{Tc}= \\
48^{\circ} \mathrm{C}\end{array}$ & $\mathrm{R} 152 \mathrm{a}$ & $\begin{array}{c}0.5 \mathrm{bar} \\
(18 \%)\end{array}$ \\
\hline $\begin{array}{c}\text { Present } \\
\text { work }\end{array}$ & 5274 & $30-55$ & $\mathrm{R}-22$ & $\begin{array}{c}0.2 \mathrm{bar} \\
(20: 33 \%)\end{array}$ \\
\hline
\end{tabular}

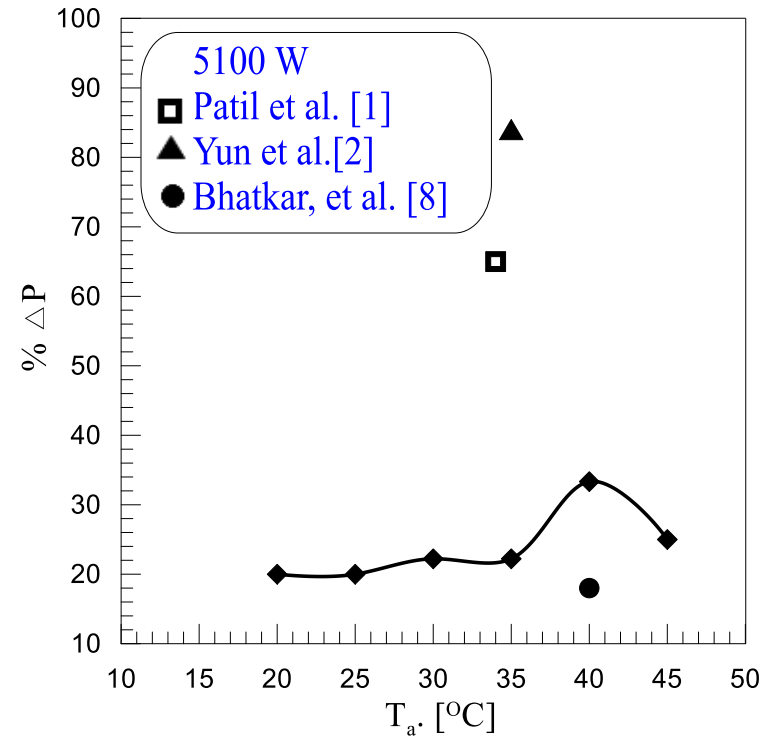

Fig. 12 Comparison of percentage savings in condenser pressure drops.

\section{3 Heat Transfer Coefficient}

The convective heat transfer coefficient for condensation inside round tubes and in microchannel is given by Eqs. (4) and (5) respectively.

For round tube [17]:

$$
\bar{h}=0.555\left[\frac{g \rho_{l}\left(\rho_{l}-\rho_{v}\right) k_{l}^{3} i_{a v}^{\prime}}{\mu_{l} d_{i}\left(T_{s}-T_{w}\right)}\right]^{0.25}
$$

For microchannel [18]:

$$
\bar{h}=0.943 \frac{k}{d}\left[\frac{\rho\left(\rho_{l}-\rho_{v}\right) g i_{a v}^{\prime} L^{3}}{k_{l} \mu_{l}\left(T_{\text {sat }}-T_{\text {wall }}\right)}\right]^{0.25}
$$

The parameters in the two equations are obtained at condensing temperature corresponding to different ambient temperature for the case of using $5274 \mathrm{~W}$ cooling capacity unit. The convective heat transfer coefficient for both finned tube condenser and microchannel is calculated and represented in Fig. (13). The figure indicates that, the use of microchannel condenser instead of finned tube one leads to increase the heat transfer coefficient during condensation of R22 inside tubes at the specified conditions in this work. The inside heat transfer coefficient is ranged between 409.5 and $486.7 \mathrm{~W} / \mathrm{m}^{2}$.K for the unit with finned round tube condenser while it was changed to be ranged from 852.7 to $1003.2 \mathrm{~W} / \mathrm{m}^{2} . \mathrm{K}$ for the unit used microchannel condenser. For all tests, the internal heat transfer coefficient of the micro-channel condenser is (205:211\%) greater than that of the finned tube condenser. The increase of heat transfer coefficient resulting in increasing of heat transfer rate and decreasing in the condenser size.

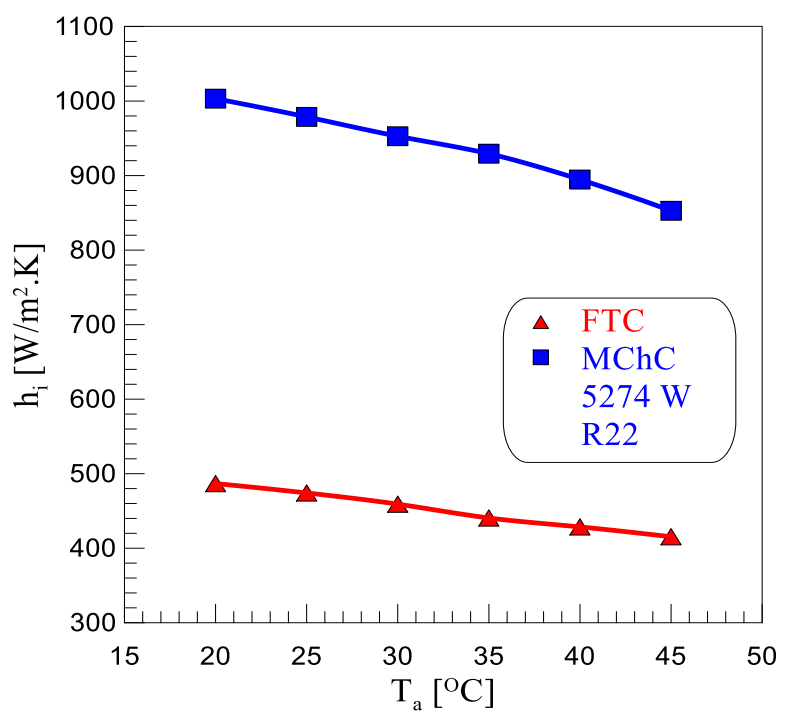

Fig. 13 Convective heat transfer coefficient

For theoretical calculation, the convective heat transfer coefficient by using other types of refrigerants [R134a, R404A and R410A] is calculated and illustrated in Fig. (14) for the two types of condenser. It is noticed that, the convective heat transfer coefficient that achieved by microchannel condenser at all types of refrigerants is (204\% to $214 \%$ ) greater than that of the fin-and-tube condenser. The figure indicates also the comparing of convective heat transfer coefficient $" h_{i}$ " in the case of using microchannel condenser using R-22 with other refrigerants. It is seen that, Freon R134a achieved a percentage decrease in the heat transfer coefficient " $\mathrm{h}_{\mathrm{i}}$ " by about (3.1:6.1\%). Refrigerant 404A achieved a percentage decrease of $(25: 33.6 \%)$ at specified 


\section{Mostafa A. Abdel-Baky, Mousa M. Mousa, Abdel-Fattah A. Koraim, " An Investigation of Using Microchannel Condenser to Improve the Performance of Air Conditioning Unit"}

operating ambient temperature. For R410A, the heat convection coefficient at ambient temperature less than $23^{\circ} \mathrm{C}$ is nearly increased with small percentage than that of R-22, after that it decrease gradually until it achieves a percentage decrease of $(10.6 \%)$ at ambient temperature of $45^{\circ} \mathrm{C}$. The figure indicates that the value of convective heat transfer coefficient achieved by the present work is nearly close to that obtained by [R134a \& R410a] and greater than that obtained R404A.

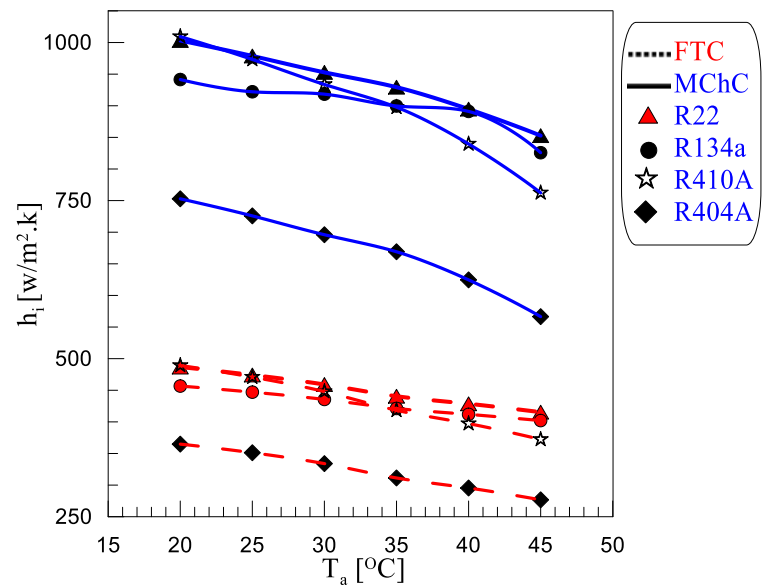

Fig. 14 Comparison of Convective transfer coefficient calculation between different Freon types

The convective heat transfer coefficient for microchannel condenser is compared also with other using different correlations of heat convection coefficient in parallel microchannel $[13,14,15,16]$. The results obtained are shown in table 4 and illustrated in Fig. 15 while the percentage deviation between this work and the others are indicated in Fig. 16. It is clearly seen that, the heat convection coefficient obtained in this work is nearly close to the correlation of Kim [16], Eq. (6). However, the heat convection coefficient obtained by Kim correlation is less than that of this work by about $(2.2: 3.4 \%)$.

$\bar{h}=5.03 \operatorname{Re}_{L o}^{1.3} \operatorname{Pr}_{L}^{0.333} k_{L} / D$

$\operatorname{Re} \leq 50000,60 \leq \mathrm{Nu} \cdot \operatorname{Pr}_{L}^{-0.333} \leq 400$

The values of $\left(\mathrm{h}_{\mathrm{i}}\right)$ that obtained by Heun, [13], correlation (7), recorded a percentage increase ranged between $(15.5: 22.8 \%)$ as indicated the tables and figures.

$\bar{h}=0.023 \operatorname{Re}_{L T}^{0.8} \operatorname{Pr}^{0.4} k_{L} / D$

Fernando [14] and Shah [15] correlations (8) and (9) recorded a decrease of the convective heat transfer coefficient ranged between (46.4:54.4\%) for Fernando and (29.35:31.15: \%) for Shah.

$$
\begin{aligned}
& \bar{h}=[0.0037 \mathrm{Re}+5.532] \operatorname{Pr}^{0.4} k_{L} / D \\
& \bar{h}=1.32 \operatorname{Re}_{L o}^{-1 / 3}\left[\frac{\rho\left(\rho_{l}-\rho_{G}\right) g k_{l}^{3}}{\mu_{l}^{2}}\right]^{1 / 3}
\end{aligned}
$$

Table (4): Comparison of value convective heat transfer coefficient after using other types of Condensation heat transfer correlations.

\begin{tabular}{|c|c|c|c|}
\hline $\begin{array}{c}\text { Paper } \\
\text { No. }\end{array}$ & $\mathrm{T}_{\mathrm{a}}\left[{ }^{\circ} \mathrm{C}\right]$ & $\begin{array}{c}\mathrm{h}_{\mathrm{i}}[\mathrm{MChC}] \\
\mathrm{W} / \mathrm{m}^{2} . \mathrm{K}\end{array}$ & $\begin{array}{c}\mathrm{h}_{\mathrm{i}}[\mathrm{MChC}] \\
\%\end{array}$ \\
\hline$[13]$ & $20-45$ & $\begin{array}{r}1299.2: 1046 . \\
7\end{array}$ & $22.8: 15.5 \%$. \\
\hline$[14]$ & $20-45$ & $537.3: 389$ & $54.4: 46.4 \%$. \\
\hline$[15]$ & $20-45$ & $690.7: 602.4$ & $\begin{array}{c}31.15: 29.35 \\
\% .\end{array}$ \\
\hline$[16]$ & $20-45$ & $980.5: 833.7$ & $2.2: 3.4 \%$. \\
\hline $\begin{array}{c}\text { Present } \\
\text { work }\end{array}$ & $20-45$ & $1003.2: 852.7$ & - \\
\hline
\end{tabular}

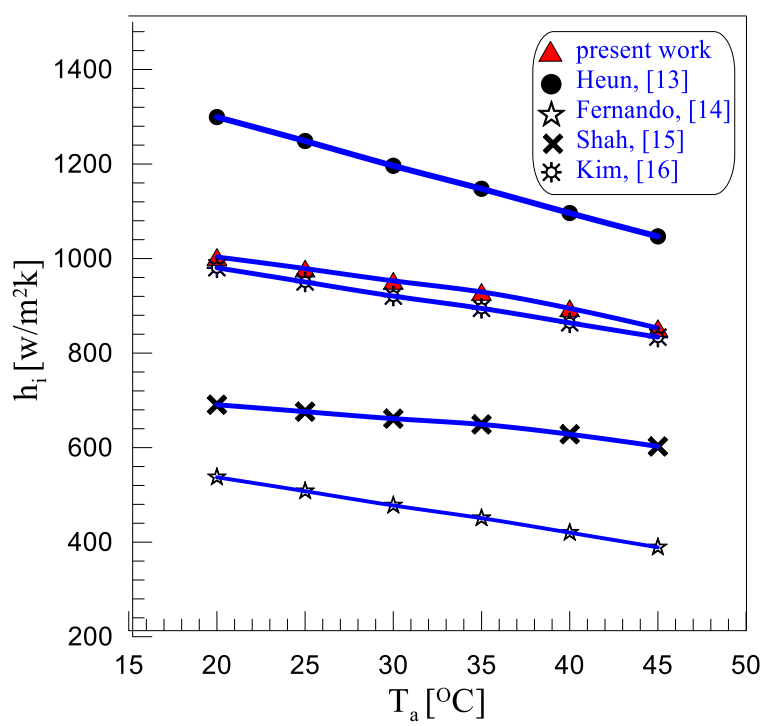

Fig. 15 Percentage deviation of Convective heat transfer between the present work and previous works 


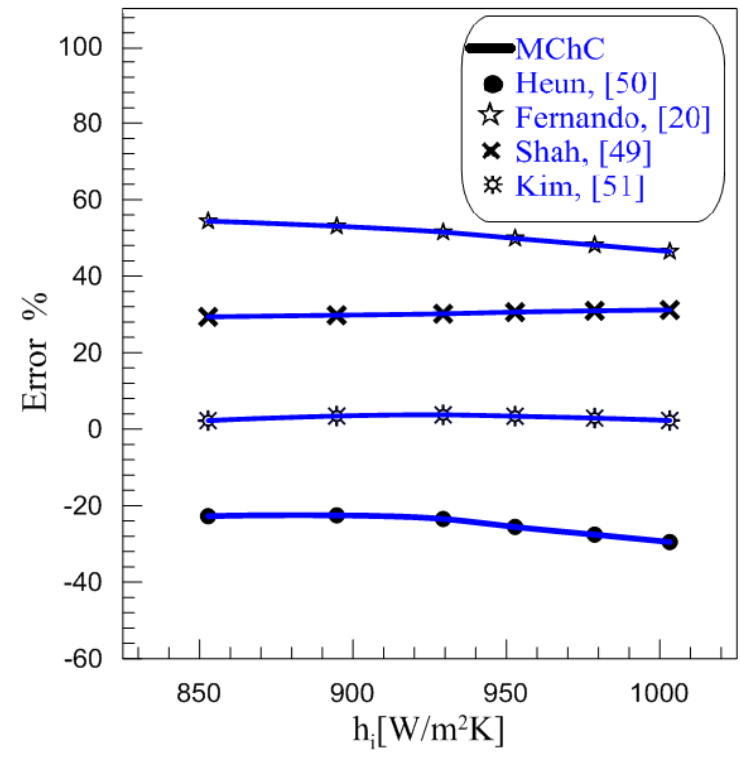

Fig. (16) Percentage deviation of convective heat transfer between the present work and some previous work

\section{4- Conclusions}

In this study, air conditioning systems with a micro channel condenser and finned tube one were experimentally and theoretically examined. The study was conducted on $(3516 \mathrm{~W}$ and $5274 \mathrm{~W})$ split air conditioners with refrigerant R-22. From the previous discussion, it can be concluded that:

1- For types of condenser systems (microchannel and a finned tube condenser), the EER and cooling capacity decrease with increasing outdoor temperatures.

2- The EER of the two units ( $3516 \mathrm{~W}$ and $5724 \mathrm{~W}$ ) with the microchannel condenser is higher than that with the finned tube condenser by $(4.3: 11.3 \%$ and 9.5:29\%) respectively.

3- The pressure drop in the microchannel condenser is less than that of (FTC) by around (20\% to $30 \%)$ r, due to the increase in the cross sectional area and the decrease in the path that the refrigerant moves in.

4- The use of microchannel condenser instead of finned tube condenser leads to increase the convective heat transfer coefficient by (205:211\%).

\section{Nomenclature \\ Symbols}

${ }^{\circ} \mathrm{C} \quad$ Celsius degree.

d Diameter, $\mathrm{m}$

EER Energy Efficiency ratio.

$\mathrm{f} \quad$ Friction coefficient.

h Convective heat transfer coefficient, $\mathrm{W} / \mathrm{m}^{2} \mathrm{~K}$ $\bar{h} \quad$ Mean convective heat transfer coefficient, $\mathrm{W} / \mathrm{m}^{2} \mathrm{~K}$

$i \quad$ Enthalpy

$K \quad$ Constant, depends on geometry.

$k \quad$ Thermal conductivity of the fluid, W/m.K

$L \quad$ Length, $\mathrm{m}$

$\mathrm{Nu} \quad$ Nusselt number

$p \quad$ Pressure, bar

Pr Prandtl number, dimensionless

Q Cooling Capacity

Re Reynolds number

$\Delta \mathrm{p} \quad$ Pressure drops.

U Velocity, $\mathrm{m} / \mathrm{s}$

T Temperature

wbt Wet-bulb temperature, C.

\section{Greek Symbol}

$\begin{array}{ll}\rho & \text { Density, } \mathrm{kg} / \mathrm{m}^{3} . \\ \mu & \text { Dynamic viscosity, } \mathrm{kg} / \mathrm{m} . \mathrm{s} . \\ v & \text { Kinematic viscosity, } \mathrm{m}^{2} / \mathrm{s} .\end{array}$
Abbreviation
AHU. Air handling unit
ARI Air-Conditioning and Refrigeration Institute
CPU Central Processing Unit
Dbt Dry-bulb temperature, C
EER Energy efficiency ratio
FTC Finned tube condenser
HVAC Heating, ventilation, and air conditioning.
JIS Japanese Industrial Standards
MChC Micro-channel heat condenser
R-134a Refrigerant 134a.
R-152a Refrigerant 152a.
R-22 Refrigerant 22.
R-410A Refrigerant 410A.
RTD Resistance Temperature Detectors
SEER Seasonal energy efficiency ratio
$\mathrm{T}_{\mathrm{a}} \quad$ Ambient Temperature. $\left[{ }^{\circ} \mathrm{C}\right]$

$\begin{array}{ll}\text { Subscript: } & \\ a v & \text { Vaporization } \\ \text { a } & \text { Ambient } \\ \mathrm{G} & \text { Gas } \\ \text { i } & \text { inside } \\ \text { in } & \text { Inlet } \\ l & \text { Liquid } \\ \text { Ou } & \text { Outlet } \\ \text { Sat } & \text { Saturation } \\ \text { W } & \text { Wall } \\ \text { v } & \text { Vapor }\end{array}$

\section{References}

1- D. P. Patil, J. H. Bhangale and K. S. Deshmukh, "Experimental Analysis of Refrigeration system 


\section{Mostafa A. Abdel-Baky, Mousa M. Mousa, Abdel-Fattah A. Koraim, "An Investigation of Using Microchannel Condenser to Improve the Performance of Air Conditioning Unit"}

using Micro-channel condenser \& Round Tube condenser" Int. J. Innovative Research in Advanced Engineering (IJIRAE) ISSN: 23492163 Vol. 1 Issue 5, June 2014.

2- Rin Yun, Yunho Hwang, Reinhard Radermacher and Rebeka Zecirovic, "Comparison of Performance of a Residential Air Conditioning System Using Micro channel and Fin and Tube Heat Exchanger", International Refrigeration and Air Conditioning Conference, Purdue, July 17-20, 2006.

3- P. Fernando B. Palm, T. Ameel, P. Lundqvist and E. Granryd,. "A mini-channel aluminum tube heat exchanger part III: Condenser performance with propane". Int. J. Refrigeration 31, pp, 696-708, 2008.

4- Xueqing Chen, Ying Chen, Lisheng Deng, Songping Mo and Haiyan Zhang. "Experimental verification of a condenser with liquid vapor separation in an air conditioning system" Applied Thermal Engineering, 51, 48-54, March2013.

5- Chang Yong Park and Pega Hrnja, "Experimental and numerical study on microchannel and round tube condensers in a R410A residential air conditioning system" Int. Journal of refrigeration 31, 822- 831, 2008.

6- Kurt W. Roth, Detlef Westphalen, John Dieckmann, Sephir D. Hamilton, William Goetzler, TIAX., "Energy consumption characteristics of commercial building HVAC systems" Volume III: Energy savings potential. Final Report to U.S. Department of Energy, Office of Building Technologies, July 2002.

7- J.S. Hu and C.Y.H. Chao, "An experimental study of the fluid flow and heat transfer characteristics in micro-condensers with slug-bubbly flow", Science direct, Int. J. Refrigeration, Vol. 30, , pp. 13091318, 2007.

8- V. W. Bhatkar, V. M. Kriplani and G. K. Awari, "Experimental Performance of R134a and R152a Using Micro-channel Condenser" Journal of Thermal Engineering, Vol. 1, Special Issue 2, No. 7, pp. 575-582, February, 2015.

9- Satish G. Kandlikar, "History, advances, and challenges in liquid flow and flow boiling heat transfer in micro-channels: a critical review", Proceedings of the 14th International Heat Transfer Conference IHTC14-23353, Washington, DC, USA, August 8-13, 2010.

10- Madhu Jhariya, P. K. Jhinge and R.C. Gupta. "Experimental study on performance of condenser of two different types used in window air conditioner" Int. J. current research and academic review, ISSN: 2347-3215 Vol. 1 pp. 35-41, Number 4, 2013.
11- Bruce R. Munson, Theodore H. Okiishi, Wade W. Huebsch and Alric P. Rothmayer, "Fundamentals of Fluid Mechanics" 7th ed. John Wiley \& Sons, Inc., 2013.

12- Atthakorn Chaikhumrop and Worrasid Trutassanawin, "Study, and Testing of a SplitType Air Conditioning Unit by Using Microchannel Condenser" The Second TSME International Conference on Mechanical Engineering, Krabi. October 19-21, 2011.

13- Heun. M. K. and Dunn. W. E., "Performance and Optimization of Microchannel Condensers", Air Conditioning and Refrigeration Center University of Illinois Mechanical \& Industrial Engineering Dept. July 1995.

14- P. Fernando, B. Palm, T. Ameel, P. Lundqvist and E. Granryd, "A mini-channel aluminum tube heat exchanger - part III: condenser performance with propane". Department of Energy Technology, Division of Applied Thermodynamics and Refrigeration, Royal Institute of Technology (KTH), SE-100 44 Stockholm, Sweden Int. J. Refrigeration 31, 696-708, 2008.

15- Mirza M. Shah, "A correlation for heat transfer during condensation in horizontal mini/micro channels", International Journal of Refrigeration, S0140-7007(15)00386-2 (2016).

16- S.-M. Kim, I. Mudawar, "Flow condensation in parallel micro-channels - Part 2: Heat transfer results and correlation technique", International Journal of Heat and Mass Transfer55, 984-994 (2012).

17- Holman, J. P., John Lloyd, "Heat transfer", 10hㅡㄹ Ed. Department of Mechanical Engineering Southern Methodist University, Michigan State University "ISBN 978-0-07-352936-3-ISBN 0-07352936-2(2010).

18- Satish G. Kandlikar, Srinivas Garimella, Dongqing Li, Stéphane Colin AND Michael R. King, "Heat transfer and fluid flow in minichannels and microchannels", Mechanical Engineering Department Rochester Institute of Technology, NY, USA, ISBN: 0-0804-4527-6 (2006). 